International Journal of Social and Administrative Sciences

$\operatorname{ISSN}(e): 2521-0556$

DOI: 10.18488/journal.136.2021.61.36.54

Vol. 6, No. 1, 36-54.

(C) 2021 AESS Publications. All Rights Reserved.

URL: www.aessweb.com

check for
updates

\title{
FACTORS FOR JOINING VILLAGE COMMUNITY NETWORKS IN TANZANIA
}

Rasel Madaha

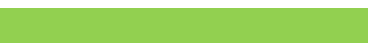

Article History

Received: 12 February 2021 Revised: 16 March 2021

Accepted: 19 April 2021

Published: 6 May 2021

\section{Keywords}

Push-pull factors

Village community networks

(VCONES)

Women

Gender

Tanzania
Sokoine University of Agriculture, Tanzania.

Email:rasel.madaha@sua.ac.tz Tel:0767716155
Theck for updates

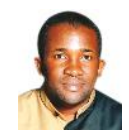

\begin{abstract}
Self-created social networks play key role in the development of communities across the globe. Self-created community networks serve as platforms for social networking among marginalized communities in Africa and the rest of the world. Although community members are motivated to network, social networks face some micro and macro structural challenges. Despite the challenges, community members continue to join and benefit from social networks. However, the reasons for them to join the networks, especially in the African context, are inadequately documented. Using a qualitative methodology and longitudinal research design, the article explores "push and pull" factors for joining a strand of self-created social network known as Village Community Networks (VCONEs). The findings suggest that challenges emanating from the neoliberal context push some community members to join VCONEs. The push prompts them to seek some protection against the negative forces of neoliberalism. VCONEs also pull women to access opportunities offered by the network. Noteworthy, VCONEs have managed to retain some autonomy from external agents such as local governments, donor and NGOs. The autonomy from external agencies makes VCONEs more sustainable than other strands of social networks.
\end{abstract}

Contribution/ Originality: The study adds to a push-pull theory by highlighting the existence of push and pull factors that draw people into social networking and entrepreneurship in a rural context. The article further adds to the theory of social network through the innovative application of the push-pull theory in exploring social networking.

\section{INTRODUCTION}

Self-created community networks play key role in the development of communities across the globe. Selfcreated community networks serve as platform for social networking among marginalized communities. According to Scott and Liew (2012) social networking emanates from the convergence of community development and participatory democracy philosophies and practices to address challenges of marginalized communities. Members of social networks benefit through accessing useful information, social support, and status. Even though, self-created community social networks are not an easy undertaking. They face some challenges such as negative gossip and undermining of their abilities at the local or micro level (see (Borgatti, Mehra, Brass, \& Labianca, 2009; Ellwardt, Labianca, \& Wittek, 2012; Kilduff \& Brass, 2010; Scott \& Liew, 2012)). At the macro level, the social networks are not immune from exploitative forces associated with the neoliberal market economy. Noteworthy, the social networks remain complex social structures that require good entrepreneurial and management skills (Madaha, 2018; Madaha, 2020; Scott \& Liew, 2012). 
Despite the challenges, grassroots people continue to join a variety of community social networks voluntarily. However, past research (see (Borgatti et al., 2009; Ellwardt et al., 2012; Kilduff \& Brass, 2010; Scott \& Liew, 2012)) has not adequately documented the motivation for joining social networks in the African context and the Tanzanian context in particular. As such, this article explores push and pulls factors for joining a strand of self-created community networks known as Village Community Networks (VCONEs). According to Madaha (2021) VCONEs are self-created autonomous collectives of grassroots women whose primary purpose is to provide autonomy, microloans, simple savings, and self-insurance.

Although VCONEs have adopted some of the features of conventional rotating and saving collectives, they maintain autonomy through avoiding external interference from local governments, donor and NGOs. They, among other things maintain autonomy through paying for external support, if they need it. That is, VCONEs are created by the members, with minimum or without external support. The autonomy also enables them to create rules and regulations in line with their local context and needs. The mentioned feature tends to make VCONEs sustainable in their interventions and immune to some of the negative effects of the market economy (Madaha, 2021). However, the documentation of the push and pull factors for joining VCONEs remains limited. An understanding of the push and pull factors can aid in the efforts towards community development and sustaining VCONEs.

\section{MAJOR LINES OF THOUGHTS INFORMING SOCIAL NETWORKING AND ASSOCIATED CONTEXT}

The article is informed by social network theory and the Push-pull theory of entrepreneurship. It also draws some useful insights from social economy tradition, and socialist feminism. The first line of thought is social network theory. Marineau, Labianca, Brass, Borgatti, and Vecchi (2018) acknowledges that one of the major theses of the social network theory is that formal and informal networks serve as hubs of social relationships among members. Marineau et al. (2018) further states social networks serve as channels through which resources flow. In this regard, the individual members need to have a correct perception of the benefits of their network to make the best use of such resources. Social network theorists categorize social networks into "bonding or horizontal" and "bridging or vertical" networks. Friends, family and closely related groups with strong communal obligations tend to form bonding networks. Community members with similar interests but with less communal obligations, form bridging networks (see (Narayan, 1999; Putnam, 2000)). Bridging networks provides linking enabling members to gain influence and resources outside their usual spheres. That is, although community members form 'bonding' networks for mere survival, they form bridging networks for economic and related benefits (see (Woolcock, 2001; Woolcock \& Narayan, 2000)). Tulin, Mollenhorst, and Volker (2021) acknowledges that social networks of persons who are dissimilar with regard to sex, age, ethnicity, and education are lost faster than networks of similar persons.

The second line of thought is the push-pull theory. The push-pull theory of entrepreneurship offers an avenue for analysing motivational factors which attract marginalized women to network. Verheul, Thurik, Hessels, and Zwan (2010) highlight that pull factors are opportunities that pull people into entrepreneurship whereas push factors are individual challenges that force people into entrepreneurship. The theory is also common in other fields such as tourism (see Nikjoo and Ketabi (2015)) entrepreneurship (see Verheul et al. (2010)) political science and development (see Kuhn (2018)). This is also an attempt to use the theory in social capital within an African context.

The third line of though is the social economy theory. According to Say (1803) social economy tradition focuses on a comprehensive examination of the function of the different components of society. Here, the economy is treated as a human body whereby the economy is one of the vital organs of the body. The other vital organs of a society are political, social, cultural and spiritual organs. The organs need to be in tandem with one another for any society to thrive. That is, if the focus is only on the economy, the other organs of the society become weak. Recent social economics theorists challenge orthodox economic approaches by calling upon the reinstatement of the social 
dimensions of economic life. They investigate the relationships and dynamics between the economy and society, and discuss the conditions and institutions requisite for a good society as well as a sustainable, just and efficient economy ${ }^{1}$. They strive to produce theories and metrics to grasp the complex and diverse nature of economic behaviour and systems that interact with values, interests and considerations outside the economic realm (Christoforou, 2018).

O'Boyle (1996) argues that social economic theory refutes the foundations of the economic discipline. The economic discipline is embedded in the thesis that every economic agent is strictly an individual being, self-interest alone drives economic behaviour and the common good is served through the invisible hand of the free market. Citing William Waters, O’Boyle (1996) further highlights that, economic policy emanates from philosophical premises that precede and determine empirical observations. According to O'Boyle (1996) there are five themes of Social Economics. The themes are the origins of values and premises in social economics; producing efficiently, turning a profit, and investing it; justice, solidarity, and community; repairing the dysfunction of capitalist economies; and the transition from command economies. This article is centred around the third theme on justice, solidarity and community.

As it is the case with the fourth line of thought (i.e. socialist feminism), social economic theory focuses on the radical project of flourishing differences, which enable alternative class, gender, sexual, and racial ways of being. The view is also referred to as postmodern Marxist-feminist perspective, which is a strand of socialist feminism (Biewener, 2006). Socialist feminism and associated strands, as acknowledged by Brenner (2014) synthesize women's oppression by capitalism and patriarchy taking into consideration contextual issues such as race, sexuality, ethnicity, gender, and nationality. Kendall (2007) is of opinion that socialist feminists analyse women's dual roles as paid and unpaid workers in a capitalist market economy to understand women's oppression and the superiority of men over women. That is, although capitalism leads to exploitation of marginalised women at the workplace, patriarchy exploits marginalised women at home (see Sarker (2006)). Socialist feminism synthesizes issues of inequality within the neoliberal context; informs the Gender and Development (GAD) approach (Parpart, Connelly, \& Barriteau, 2000) enshrined in the Tanzania National Women Development and Gender Policy (URT, 2000a); brings on board community development issues calling for women to capitalize on collective power (Mohanty, 2002).

\section{REVIEW OF PAST RESEARCH ON JOINING SOCIAL NETWORKS}

Overall, networking is a risk-taking adventure and requires an entrepreneurial effort. Past research highlights that marginalized women and men are motivated to network with others to deal with oppressive forces such as neoliberalism and patriarchal exploitation (Bujra, 1990; Eisenstein, 2009; Madaha, 2014; Mohanty, 2002; Tripp, Casimiro, Kwesiga, \& Mungwa, 2009; Tulin et al., 2021). This study focuses on networking among rural women in Tanzania to capture recent developments in social networking. Networking of women in the Tanzanian context is not a new phenomenon. Based on past research, Tanzanian women network to form formal and informal collectives for a number of reasons (see (Archambault, 2010; Chachage \& Mbilinyi, 2003; Geiger, 1997; Koda et al., 1987; Mallya, 2005; Meghji, Meghji, \& Kwayu, 1985; Tripp et al., 2009)).

First, Tanzanian women come together to address increased financial obligations originating from the adoption of neoliberal policies (Tripp et al., 2009). In mid-1980s, Tanzania shifted from a socialist welfare interventionist state (that provided some free social services) to a neoliberal state (that provided less free social services). The socialist welfare state was in existence from 1967 to mid-1980s (Hyden, 1980). According to Tripp et al. (2009) over $50 \%$ of the Tanzanian population had membership in informal grassroots networks at the outset of neoliberal

${ }^{1}$ (Association for Social Economics, http://www.socialeconomics.org/). 
market reforms in mid-1980. The cost share programs were burdensome to marginalized women because men's incomes from formal and informal sector were insufficient for the household (Bujra, 1990; Tripp, 1994).

Secondly, some local and international development agencies have been encouraging women to network. The agencies attract women to form networks in an attempt to integrate them into the dominant profit driven economic agenda. The catchphrase of such measures is Women in Development (WID). The WID approach was part of the developmental interventions of some neoliberal institutions such as the World Bank and International Monetary Fund's (IMF) in 1980 s and 1990s. The WID projects informed Structural Adjustment Programs (SAPs) (see (Chachage \& Mbilinyi, 2003; Koda et al., 1987; Tripp, 1994)). However, the WID projects and associated SAPs failed to integrate the marginalised communities into the development process. Gender and Development (GAD) emerged in 1990 s to address some of the weaknesses of the neoliberal market reforms. Some development agencies use the GAD approach to encourage networking among women in an attempt to free them from exploitation and oppression caused by the market economic reforms and patriarchy (Chachage \& Mbilinyi, 2003; Koda et al., 1987; Madaha, 2020; Madaha, 2021; Tenga \& Peter, 1996; Tripp, 1994). Even though, the challenge with externally driven interventions is unsustainability at the end of the external intervention.

Thirdly, some Tanzanian women seek membership in networks to access resources such as knowledge, skills, and competencies (see (Madaha, 2020; Madaha, 2021; Madaha, 2014; Mallya, 2005; Tripp et al., 2009)). Madaha (2014) highlights the Tanzanian women have facilitated the creation of a formal structured movement to address gender issues. Mallya (2005) learned that Tanzanian women network to access finance resources, expert personnel, increased legitimacy, and wider media coverage.

Fourthly, Tanzania women are motivated to join women networks to access community insurance. Archambault (2010) acknowledges that women networks serve as safety nets that create a sense of belonging to women. Even though, the gap on mutual insurance as practised by VCONEs remains and needs to be filled by another study.

Fifthly, women join women's networks because such networks offer a cultural engrained platform for women to address their local problems and needs. McClean (2000) is of opinion that women networks, "offer indigenous approaches or context specific frameworks to solving women's problems in their specific environments by focusing on action, developing programs and institutions." Some scholars who have studied Tanzania women's movement, share similar views (Archambault, 2010; Geiger, 1997; Koda et al., 1987; Madaha, 2014; Tripp, 1989). A case study by Msonganzila (1994): WS85-WS86) reveals that, the spirit of self-help and pooling of resources by the members of a community to achieve individual benefits was a common practice in pre and post-colonial societies.

Overall, past research (Tripp, 1994) and recent research (Madaha, 2021) divulge that neoliberal policies have challenged gender roles in the Tanzanian context. Some women have become breadwinners in their households. Women have specifically created organizations based on economic survival believing that their survival is reliant on the survival of others. Overall, the review of past research highlights an inadequate focus on "push and pull" factors to form and join self-created networks. The mentioned gap is going to be covered by this study.

\section{DATA COLLECTION AND ANALYSIS}

This article is based on an unpublished PhD study of the University of Dar es salaam conducted from 2015 to 2017 and a follow up study conducted from 2018 to 2021. The author applied a qualitative longitudinal and exploratory study involving multiple interactions with the study participants at the study location. The author selected Mkalama district as a case study to explore the survival of local communities following welfare intervention program by a donor from 1994 to 2009. There was also some evidence of on-going autonomous networking activities among women that was independent from external donors and other development agencies. The author collected data through field participant observations by living among the study population, focused groups discussions, and documentary review. Other data collection methods were in-depth interviews, key 
informant interviews and face to face interviews using semi-structured questionnaires. The author also videoed some of the FGDs and audio recorded some of the interviews to preserve data collected in their original form as much as possible.

Some of the techniques of Action research were also applied to sustain the relationships with the study population. In this regard, the author sustains the relationship with the VCONEs through a local not-for-profit NGO called JUWAKI (Jumuiya ya Wafanyabiashara Wanawake Kinyangiri) and AGEN (Affirmative action on Gender Equality Network). JUWAKI is an Association of Women small Entrepreneurs. The author founded AGEN in 2011 to empower grassroots and marginalized women across Tanzania mainland. The official website of AGEN is www.agentz.org

The author selected five wards out of fourteen administrative wards of Mkalama district. The wards are Iguguno, Msingi, Kinyangiri, Nduguti and Kikhonda (see Table 1). The author identified and selected 13 VCONEs (see Table 1) from the mentioned wards. The wards were selected because they had active VCONEs that had been in existence for at least 5 years.

Table-1. VCONEs in Selected Wards of Mkalama District.

\begin{tabular}{l|l|c}
\hline Ward's Name & Women's Network Name & Number of Members \\
\hline \multirow{4}{*}{ Iguguno } & Upendo Care & 30 \\
\cline { 2 - 3 } & Family Care & 30 \\
\cline { 2 - 3 } & Upendo & 30 \\
\hline \multirow{4}{*}{ Kinyangiri } & Nzalilya & 30 \\
\cline { 2 - 3 } & Jikomboe & 23 \\
\cline { 2 - 3 } & Juhudi & 31 \\
\hline \multirow{5}{*}{ Kikhonda } & Uchumi-Msingi & 22 \\
\cline { 2 - 3 } & Tumaini & 11 \\
\cline { 2 - 3 } & Nguna & 22 \\
\hline & Jitume & 40 \\
\cline { 2 - 3 } & Tupendane & 30 \\
\cline { 2 - 3 } & Faidika & 30 \\
\hline Nduguti & Mwanzo Mgumu KIKOBA Namba & 36 \\
\hline Total of Participants & & 363 \\
\hline Source: Field data. &
\end{tabular}

Finally, it is underscored here that push and pull variables were developed following a pre-test in Iringa region and review of secondary data from both Civil Societies and Local Government Authorities in Mkalama district (study area). The author conducted a pre-test at Iringa to explore scalability of the findings to other regions in Tanzania. The variables were further refined during the process of qualitative data collection across all selected wards and then was subsequently followed by a face to face interview using the refined semi-structured questionnaire. This applies to all of the tables. If a variable receives $100 \%$, it means that it was selected by all the respondents. This opposite holds true in that members who did not select the option thought that the option missed direct relationship to the issue presented. The pull variables were Communal solutions, Communal utilization, communal moral support, and joint implementation of activities (communal manual labour). The push variables were poverty, patriarchal culture, need for information, and lack of entrepreneurship skills.

The respondents are presented in the following tables. The author used snowball sampling to select the respondents (see Table 2 and Table 3). The author managed to interview 100 VCONE members and 78 spouses of the members to capture gender relations influencing the networks. 
Table-2. Basic Characteristics of VCONE members ( $\mathrm{N}=100)$

\begin{tabular}{|c|c|c|c|c|c|c|c|}
\hline Parameter & Values & Ig. & Ms & Kiny & Kikh & Total & Percentage \\
\hline \multirow{4}{*}{$\begin{array}{l}\text { Age } \\
\text { Category } \\
\text { (years) }\end{array}$} & $18-25$ & 1 & 1 & 1 & 1 & 4 & 4 \\
\hline & $26-35$ & 2 & 3 & 2 & 3 & 10 & 10 \\
\hline & $36-45$ & 11 & 10 & 11 & 10 & 42 & 42 \\
\hline & Over 45 & 11 & 11 & 11 & 11 & 44 & 44 \\
\hline \multicolumn{2}{|l|}{ Total } & 25 & 25 & 25 & 25 & 100 & 100 \\
\hline \multirow{3}{*}{$\begin{array}{l}\text { Educational } \\
\text { level }\end{array}$} & Primary & 23 & 25 & 25 & 25 & 97 & 97 \\
\hline & Vocational & 1 & $\mathrm{O}$ & $\mathrm{O}$ & $\mathrm{O}$ & 01 & 01 \\
\hline & Secondary & 1 & $\mathrm{O}$ & $\mathrm{O}$ & $\mathrm{O}$ & $\mathrm{O} 2$ & $\mathrm{O} 2$ \\
\hline Total & & 25 & 25 & 25 & 25 & 100 & 100 \\
\hline \multirow{2}{*}{$\begin{array}{l}\text { Marital } \\
\text { status }\end{array}$} & Married & 20 & 18 & 21 & 19 & 78 & 78 \\
\hline & Separated & 5 & 7 & 4 & 6 & 22 & 22 \\
\hline \multicolumn{2}{|l|}{ Total } & 25 & 25 & 25 & 25 & 100 & 100 \\
\hline
\end{tabular}

Table-3. Basic Characteristics of Male Spouses ( $\mathrm{N}=78$ ).

\begin{tabular}{|c|c|c|c|c|c|c|c|}
\hline Parameter & Values & Ig. & Ms & Kiny & Kikh & Total & Percentage \\
\hline \multirow{4}{*}{$\begin{array}{ll}\text { Age } & \text { Category } \\
\text { (years) } & \end{array}$} & $18-25$ & $\mathrm{OO}$ & $\mathrm{OO}$ & $\mathrm{OO}$ & 01 & 01 & 01 \\
\hline & $26-35$ & 01 & $\mathrm{O} 2$ & 01 & $\mathrm{O} 2$ & 06 & 08 \\
\hline & $36-45$ & 07 & 08 & 10 & 08 & 33 & 42 \\
\hline & Over 45 & 12 & O8 & 10 & O8 & 38 & 49 \\
\hline \multicolumn{2}{|l|}{ Total } & 20 & 18 & 21 & 19 & 78 & 100 \\
\hline \multirow[t]{4}{*}{ Educational level } & $\begin{array}{l}\text { Primary } \\
\text { education }\end{array}$ & 18 & 18 & 21 & 19 & 76 & 97 \\
\hline & $\begin{array}{l}\text { Vocational } \\
\text { training }\end{array}$ & $\mathrm{OO}$ & OO & OO & $\mathrm{OO}$ & $\mathrm{OO}$ & OO \\
\hline & $\begin{array}{l}\text { Secondary } \\
\text { education }\end{array}$ & $\mathrm{O} 2$ & $\mathrm{OO}$ & OO & $\mathrm{OO}$ & $\mathrm{O} 2$ & O3 \\
\hline & $\begin{array}{l}\text { No formal } \\
\text { education }\end{array}$ & $\mathrm{OO}$ & $\mathrm{OO}$ & $\mathrm{OO}$ & $\mathrm{OO}$ & $\mathrm{OO}$ & OO \\
\hline \multicolumn{2}{|l|}{ Total } & 20 & 18 & 21 & 19 & 78 & 100 \\
\hline Marital status & Married & 20 & 18 & 21 & 19 & 78 & 100 \\
\hline \multicolumn{2}{|l|}{ Total } & 20 & 18 & 21 & 19 & 78 & 100 \\
\hline
\end{tabular}

The author used snowball sampling to ensure that only respondents with quality information as per the study objectives are obtained. The author attained the saturation point (i.e. the point whereby there was no new information being identified) after interviewing 77 female VCONE members and 73 male respondents. Data saturation is a qualitative data collection technique originating from grounded theory, referring to a practice of collecting qualitative data until when there is no newer information obtained (see Charmaz (2006)). However, the author continued to interview the respondents up to 100 women and 78 women. The process further confirmed the attainment of the saturation point. The author did not manage to interview 22 husbands of VCONE members because they were away from the study location to attend other social responsibilities. The absence of 22 husbands did not cause significant problem because the data saturation point was attained after interviewing 73 husbands.

The follow up study beyond the PhD study involved 7 key informant interviews, 30 counselling sessions to leaders, and six follow up meetings with the leaders. The author conducted the follow up study as a social experiment. The author used AGEN for its inconvenience in conducting the proposed set up. In this context, AGEN operated as a regular capacity building NGO.

The data analysis involved compilation of the data into an easy form. That is, the author transcribed the data first. Then, the data originally reported in Kiswahili was translated to English. The efforts were made to ensure the translated data maintains the original details and meaning. The data were classified per study objective. Content analysis was used analyse the qualitative data. Some of the transcriptions have been included in the thesis as 
verbatim responses. The analysis of some numerical data was conducted with respect to the objectives of the study. The author developed some descriptive statistics such as frequencies and percentages to convey the findings easily.

\section{FINDINGS AND DISCUSSION}

Overall, the study identified a number of push and pull factors that drive rural women to join and form VCONEs amidst the challenges emanating from neoliberalism. However before engaging into the discussion of the push and pull factors, it worth to provide the meaning, distinction and the context in which VCONEs operate. Although the findings of this study support the view that Tanzanian women are motivated to network, both formally and informally, to earn a living, it has been learnt that networking is contextual. The findings of this study and those of the past (see (Moser, 1993; Moser, 1989)) highlight that networking is shaped by socially assigned roles of women and men. Despite the challenge, the networks continue to play a potential role in empowering marginalized communities. Consistent with recorded history of Tanzania, as shared in various key government documents (see (URT, 1988, 2000a)), the study suggests that women's networking can play a key role in building sustainable rural communities. This study provides sufficient evidence on the contribution of VCONEs to the survival and sustenance of communities in Mkalama District. The findings are in line with past research as shared by Daniel (1988) who acknowledges that women networks are integral resources in community organizing.

Documentary review shows that Mkalama district council registers VCONEs, as Community Based Organizations (CBOs) at the district's Department of Community Development. Other collectives are also registered as CBOs. Even though, one cannot identify VCONE using a district registry. The district officials have not established the distinction among the collectives. That is one can identify VCONEs using specific features. A unique contribution of this study is to identify them and label them as VCONEs. Based on the study findings, VCONEs are increasingly becoming a common phenomenon in Mkalama District. Key informant interviews and secondary sources in particular, divulge that VCONEs started around 2010 in Mkalama District. They emerged after major international NGOs such as World Vision, concluded their welfare developmental interventions in the district. An interview with the District Community Development Officer (DCDO) revealed that the interventions of the welfare developmental organizations created dependence syndrome among community members. Some of the development agencies built school classes, water wells, dispensaries, teachers' houses and houses for health workers with insufficient community participation. Subsequently, the community members established VCONEs in an attempt to cope with the withdrawal of the NGOs and associated neoliberal difficulties (District Community Development Officer, Personal communication, $17^{\text {th }}$ July, 2015)

The findings from Focused Group Discussion in Iguguno, Kinyangiri, Kikhonda and Misingi wards highlighted that the dependency syndrome of the community members continued to affect other development agencies. The services of financial institutions with a market oriented approach, including international ones, were confused for the welfare interventions. Subsequently, the institutions were not able to upscale their interventions across the district. They either minimized or terminated their operations after experiencing difficulties in the implementation of the interventions. Three FGDs from Iguguno ward supported the views. One of the community leaders said:

"FINCA and SIDO have abandoned all of their microfinance projects because the inhabitants from Iguguno ward do not pay loans. Besides, microfinance operations by the formal institutions have become extremely expensive: the institutions, among other things, lose money through unpaid loans and associated follow up expenses. Consequently, the institutions have moved elsewhere" (Key Informant, Leader of JUWAKI, $17^{\text {th }}$ May, 2015).

CARE International attempted to introduce a Grameen like Village Community Banks (VICOBAs) networks around early 2010s. The local communities labelled them "Vikundi vya Care" in English, "CARE established Groups" 
(CeGs). Three focused groups in Kikhonda acknowledged that all the 20 CeGs in the ward collapsed after CARE left the ward (See Box 1).

Box-1. Failure of CARE international microfinance projects.

The members of CeGs expected some free services from CARE International. However, unlike World Vision, CARE International focused on capacity building training as opposed to provision funds to the groups. The community members maintained their membership to CeGs in the hope of getting funds upon completion of training. However, all of the CeGs collapsed after CARE International concluded its training project and departed from the district.

Source: FGDs with members of VCONE in Kikhonda Ward, 01/07/15.

The withdrawal of the financial institution has left grassroots people of Mkalama District and women in particular with no options other than increasingly relying on establishing VCONEs to meet their growing financial needs. Noteworthy, FGDs across all Wards have divulged that VCONEs are a modified form of CeGs which have taken the local context on board (see Box 2).

Box-2. Relationship between VCONEs and CeGs.

VCONEs have kept some of the practices of CeGs such as keeping a wooden box and holding weekly meetings. However, members of VCONEs mobilize their resources to meet operational expenses. For example, although the wooden boxes and record books were provided to CeGs free of charge in the past, VCONEs purchase the boxes from SIDO in Singida town. The price of boxes and record books ranged from Tanzanian Shillings 80,000 to Tanzanian Shillings 100,000 in 2015. Nevertheless, some of the VCONEs do not possess such boxes. Instead, their funds are kept by trustworthy members holding positions as treasurers.

Source: FGDs in Iguguno and Kinyangiri, 13/05/15, Kikhonda and Msingi 14/05/15.

Likewise, VCONEs have kept some elements of VICOBA scheme. An ideal VICOBA scheme allows members to voluntarily form a group and save money, through purchasing shares, to create a cumulative fund from which members can borrow and repay microloans with a small interest. Here, they follow a time bound annual cycle of savings and lending. At the end of each cycle, the earnings are audited to know the proportion owned by each member. However, the proceeds are not shared among members but the whole amount is left to accumulate indefinitely (see Box 3).

Box-3. Features of an Ideal VICOBA Scheme.

The cycle of savings and lending is time bound. At the end of an agreed period (the 'cycle'), the accumulated savings and service charge earnings are audited to know the proportion of the amount that each member has saved throughout the cycle. This is critical for resolving outstanding issues; for transparency and for maintaining the confidence of the members. Associations agree on the length of the operating cycle and this is recorded in the constitution. A cycle should not be less than nine months, or longer than a year. However, despite of the audit done, the proceeds are not shared out conventionally. The whole amount of savings are left to grow and built on top over the next cycle

Source: WWF (2010).

Unlike VICOBA, VCONEs allow members to share the proceeds and return shares to each member at the end of an "annual cycle." The annual cycle of VCONEs usually takes of 12 months equivalent to a year of contributing to a cumulative fund. The cumulative fund is further increased by interests charged on loans given to members (see Box 4).

Overall, VCONEs are an outcome of difficulties emanating from neoliberalism. The findings suggest that rural communities are not desperate victims of neoliberalism and associated difficulties (see Harvey (2014)). They can take communal measures to deal with such difficulties. The findings further suggest that development agencies need to help communities make the best use of their locally available resources as opposed to providing them with free hand-outs. Interventionist welfare approach creates dependency to the local communities on external assistance. 
Box-4. Features of VCONE.

The cycle is designated in such a way that it ends whenever the agricultural and rainy season begins usually on November of each year. Some VCONEs break their cycle earlier on October. The proceeds from the cumulative funds are usually invested, by individual members, in agricultural production and education of children. At this time of the year, petty businesses are the least remunerative because the members dedicate their funds in agricultural production. The practice minimizes funds that would otherwise be used for the purchase of petty business products and services. Another important feature of VCONEs is autonomy from external agencies. The decisions on how to run the VCONEs is on members' shoulders.

Source: FGDs in Iguguno and Kinyangiri, 30/06/15, Kikhonda and Msingi 01/07/15.

\subsection{Pull Factors for Joining VCONEs}

There are some opportunities that pull women to form and join VCONEs. Table 4 shows the main pull factors that draw women entrepreneurs to VCONEs. The pull factors are: a) communal solutions to social and economic problems (selected by $100 \%$ of questionnaire respondents); b) communal utilization of available resources to earn and increase household income (selected $100 \%$ of questionnaire respondents); c) accessing communal moral support during hard times (selected by 100\% of questionnaire respondents); and d) implementation of joint activities (selected by $14 \%$ of questionnaire respondents).

Table-4. Pull Factors for VCONEs $(\mathrm{N}=178)$

\begin{tabular}{|c|c|c|c|c|c|}
\hline \multirow[t]{2}{*}{ Pull Factor } & \multirow[t]{2}{*}{ Ward } & \multicolumn{2}{|c|}{$\begin{array}{c}\text { Member of VCONEs }{ }^{2} \\
N=100\end{array}$} & \multicolumn{2}{|c|}{$\begin{array}{c}\text { Spouse of Members } \\
\qquad N=78\end{array}$} \\
\hline & & Freq. & Perc (\%) & Freq & Perc. (\%) \\
\hline \multirow{4}{*}{$\begin{array}{l}\text { Communal solutions to social and } \\
\text { economic problems }\end{array}$} & Ig. & 25 & 100 & 20 & 100 \\
\hline & Kiny. & 25 & 100 & 21 & 100 \\
\hline & Kikh. & 25 & 100 & 19 & 100 \\
\hline & Ms & 25 & 100 & 18 & 100 \\
\hline \multirow{4}{*}{$\begin{array}{l}\text { Communal utilization of available } \\
\text { resources to earn and increase } \\
\text { household income }\end{array}$} & Ig. & 25 & 100 & 20 & 100 \\
\hline & Kiny. & 25 & 100 & 21 & 100 \\
\hline & Kikh. & 25 & 100 & 19 & 100 \\
\hline & Ms & 25 & 100 & 18 & 100 \\
\hline \multirow{4}{*}{$\begin{array}{l}\text { Accessing communal moral support } \\
\text { during hard times }\end{array}$} & Ig. & 25 & 100 & 20 & 100 \\
\hline & Kiny. & 25 & 100 & 21 & 100 \\
\hline & Kikh. & 25 & 100 & 19 & 100 \\
\hline & Ms & 25 & 100 & 18 & 100 \\
\hline \multirow[t]{4}{*}{ Implementation of joint activities } & Ig. & $\mathrm{O}$ & $\mathrm{O}$ & $\mathrm{O}$ & $\mathrm{O}$ \\
\hline & Kiny. & $\mathrm{O}$ & $\mathrm{O}$ & 0 & 0 \\
\hline & Kikh. & $\mathrm{O}$ & $\mathrm{O}$ & $\mathrm{O}$ & $\mathrm{O}$ \\
\hline & Ms & 14 & 14 & 3 & 4 \\
\hline
\end{tabular}

Key: Ig.= Iguguno, Kiny.=Kinyangiri, Kikh=Kikhonda, Ms.= Misingi.

It must be noted though, that pull factors are inherent features of VCONEs that attract members to join them. Details on each of the pull factors are going to be discussed in the following sub-sections.

\subsubsection{Communal Solutions to Social and Economic Problems}

The findings indicate that VCONEs provide communal solutions to social and economic problems by allowing members work together to address them (see Table 4). They do so by creating regulations in such a way that shared problems are addressed. VCONEs have created a cumulative fund to address scarcity of funds for investing in agricultural production and petty businesses. A key informant claimed that:

"VCONEs are very important in our lives. For instance, I, as a parent, have managed to educate my children and built a house with funds accrued from the networks. In addition, we usually get adequate funds for

2 "VCONE members" refers to female members of VCONE. "Spouses" refers to husbands or male spouses of VCONE members who were present at the time of data collection. This applies to all Tables. 
investments in agricultural production at the end of an annual cycle in November of each year. At this time, we break the cycle and share profit. Moreover, each member takes her shares. If the networks were not present, $I$ and my family would have suffered a lot" (Source: Interview with Key Informant, Experienced member of VCONE at Msingi ward, 23 ${ }^{\text {nd }}$ June, 2015).

The statement was reflected in face-to-face interviews and FGDs. The findings suggest that VCONEs are bridges between agricultural and non-agricultural seasons that allow members to meet their households' needs. VCONE provide financial resources to members during farm preparation. This is the time that such support is needed the most.

Consistent with past research (McClean, 2000) this study highlights that women prefer to network at the local level to access cultural engrained platforms that are useful in addressing their local problems and needs. The study findings also support a thesis that local women networks are important in the provision of local solutions to local problems.

\subsubsection{Accessing Resources and Raising Household Income}

VCONEs are resourceful in enabling members to sustain agricultural production and other kinds of petty businesses (see Table 4). VCONEs provide financial resources to the members to enable them invest in off-farming activities during the dry season. The off-farming activities that receive a significant amount of profits include sunflower oil processing food vendoring (Mama Lishe), tailoring, shop keeping, processing of various agricultural products such as maize, and stalling at a village market place selling horticultural products and cereals. Net profits earned from petty businesses range between Tanzanian shillings 40,000 to over Tanzanian shillings 600,000 per month. Women's gross earnings from investments in agricultural production, range, depending on rainfall availability, from Tanzanian shillings 600,000 to over Tanzanian 10 million per agricultural season. In a broader context, this result is in line with Solano and Rooks (2018) who provide strong evidence on the role of women's collectives in the provision of resources to the members.

However, years characterised by extended drought periods affect the agricultural production and off-farming petty businesses. According to Twigg (2015) disasters disproportionately affect women as compared to men because women's access to education, resources, income-earning opportunities and land is limited. Key informant interviews indicate that common disasters that affect the majority of women in the district are extended drought periods, HIV/AIDS, and floods. This follows the fact that women have been socially assigned the care giving role. VCONEs have played an instrumental role in rescuing women affected by the mentioned emergencies. The loans that women access from VCONEs are invested into income generating activities that enable them to earn extra incomes. The earned income is spent for their respective household expenses.

\subsubsection{VCONEs as Safety Net}

VCONEs serve as safety net by enabling members deal with threat the negative forces of a market economy (see Table 4). VCONEs have the ability to collect substantial amount of money to meet the financial needs of the members in an annual cycle. The best performing VCONE has an ability to provide a minimum of Tanzanian shillings 500,000 and a maximum of was Tanzanian shillings 1,200,000 in an annual cycle.

Further, VCONEs have established a community fund to serve emergency needs of members. The community fund is created through weekly contributions from members. The contribution ranges from Tanzanian shillings 500 to 1000 depending on the income of individual members. The community fund continues to accumulate overtime. This gives an opportunity to members, in desperate need of financial assistance, to access the funds as a short-term emergency loan. The emergency loan is repaid in less than two weeks because the funds used for the loan are meant to address emergencies. The VCONEs which contribute Tshs 1000 can accumulate up to Tshs 10,000,000 in an annual cycle. The fund also addresses some qualified non-members, especially orphans and disadvantaged children, 
who faced social calamites. Moreover, if a member fells into an emergency, some funds are deducted from the community fund. The rest of the members contributed additional funds to assist the victim.

Second, VCONEs use the community fund to provide emergency loan to members. In this situation, members repay the loan only within two weeks. The findings imply that the community fund is an innovative solution to the challenges of VCONE members within their context. The community fund is an innovation away from conventional ROSCAs. VCONE use the community fund to deal with an emergency situation following the death of a member with unpaid loan. Here, VCONE uses funds from the Community Fund and members' contributions to meet the funeral expenses of a deceased member. After a funeral ceremony, members contribute money to repay the deceased loan and stabilize the VCONE. The approach enables VCONEs to stabilize and resume operations.

In line with past research (Aina, 1998; Archambault, 2010; Enarson \& Morrow, 1998; Kabeer, 2003; Lo, 2008; WinklerPrins \& de Souza, 2005) the findings of this study suggest that women's networks serve as context specific safety nets to help members deal with context specific challenges. There are several terms referring to this phenomenon and they include human economy, moral economy and economy of affection (Swantz \& Tripp, 1996). It is argued that in such economies people hold social values to safeguard the social motivation of mutual care. The findings of this study reveal that as the context changes, members of networks devise new ways of providing mutual care to one another.

\subsubsection{Joint Implementation of Activities}

The presence of joint implementation of activities in VCONEs pulls women to join and maintain membership in the networks (see Table 4). VCONEs offer two categories of joint activities. First, Family Joint Activities (FJAs) target individual members to lessen their household chores. Second, Community Joint Activities (CJAs) target VCONEs. On one hand, FJAs lessen the daily burden of members at their respective households. This allows them to engage in other productive activities. VCONEs usually assist members to do weeding in their individual farms. This is done during weeding season. For the most part, a member, owning a farm, is required to provide members of the network with a soft drink and contribute Tanzanian shillings 5,000 to the VCONE's cumulative fund. A similar arrangement is used to jointly gather firewood for individual members. This kind of arrangement pulls new members to join VCONEs and keeps existing members from leaving. Noteworthy, all of the selected VCONEs, with exception of those in Msingi and Nduguti Wards, do not perform FJAs at a scale done in Msingi and Nduguti wards.

On the other hand, CJAs engage with capacity building of VCONEs. For instance, VCONE members (see Table 4) in Msingi and Mkalama wards of Mkalama District make arrangements to train some of their members. They have specifically established an education fund from which selected members can receive formal training. Those who have received training have an obligation to train other VCONE members.

The mentioned findings support a thesis by Twigg (2015). Specifically, Twigg is of opinion that sound networking, as understood broadly, is crucial because networking can improve access to, and exchange of, information and expertise by members. The capabilities of individual members are then maximised through partnerships and greater cooperation. These in turn can lead to community development.

\subsection{Push Factors for Joining VCONEs}

The market economy has a tendency of creating unbearable and disproportionate challenges to vulnerable populations (see Harvey (2014)). The findings of this study indicate that some marginalized women who face the challenges join VCONEs as a pathway to small scale entrepreneurship. Table 5 shows the main factors that push women to join VCONEs. The push factors are poverty, patriarchal culture, need for information, and lack of entrepreneurship skills. The individual circumstances push some of the women to VCONEs. 
Table-5. Push Factors for Women to Join Networks ( $\mathrm{N}=178$.

\begin{tabular}{|c|c|c|c|c|c|}
\hline \multirow[t]{2}{*}{ Push Factor } & \multirow[t]{2}{*}{ Ward } & \multicolumn{2}{|c|}{ Members of VCONEs $(\mathrm{N}=100)$} & \multicolumn{2}{|c|}{ Spouses $(n=78)$} \\
\hline & & Freq. & Perc.(\%) & Freq. & Perc.(\%) \\
\hline \multirow[t]{4}{*}{ Poverty } & Ig. & 25 & 100 & 20 & 100 \\
\hline & Kiny. & 25 & 100 & 21 & 100 \\
\hline & Kikh. & 25 & 100 & 19 & 100 \\
\hline & Ms & 25 & 100 & 18 & 100 \\
\hline \multirow[t]{4}{*}{ Patriarchal Culture } & $\operatorname{Ig}$. & 25 & 100 & 20 & 100 \\
\hline & Kiny. & 25 & 100 & 21 & 100 \\
\hline & Kikh. & 25 & 100 & 19 & 100 \\
\hline & Ms & 25 & 100 & 18 & 100 \\
\hline \multirow[t]{4}{*}{ Need for Information } & Ig. & 25 & 100 & 15 & 75 \\
\hline & Kiny. & 22 & 88 & 13 & 70 \\
\hline & Kikh. & 20 & 80 & 11 & 58 \\
\hline & Ms & 23 & 92 & 13 & 72 \\
\hline \multirow[t]{4}{*}{ Lack of Entrepreneurship Skills } & Ig. & 13 & 52 & 6 & 30 \\
\hline & Kiny. & 7 & 28 & 5 & 24 \\
\hline & Kikh. & 5 & 20 & $\mathrm{O}$ & 0 \\
\hline & Ms & 25 & 100 & 18 & 100 \\
\hline
\end{tabular}

The push factors are further explained in the following sub-sections.

\subsubsection{Poverty}

The study showed that women join VCONEs because they cannot meet some of the household basic needs (see Table 5). Based on past research and this research, women face difficulties in accessing financial resources from formal sources. A study in Uganda by Solano and Rooks (2018) suggests that, "female entrepreneurs generally have less financial power than men, due to difficulties in accessing financial resources via loans by formal institutions, and a lack of control over finances in the household.” In this regard, women join VCONEs to access loans that they invest in small businesses. VCONEs have increased members' accessibility to microloans. The present study found that formal microfinance institutions have complicated procedures that deny marginalized women access loans. Noteworthy, increased accessibility to microloans promote participation of women in income generating activities (see Box 5).

Box-5. Success story on increase accessibility to microloans.

Salma, from Kikhonda ward, is a member of VCONE. She joined her VCONE in 2010. She engages in petty business, agricultural production and livestock husbandry. She is married with three children. She sells plastic shoes, famously known as yeboyebo, to her customers in Kikhonda ward. She started her business in 2007 with a capital of Tanzanian shillings 70,000. She got this capital after selling three bags of sunflower seeds. She did not realise the potentiality of the business until when she got a loan from her VCONE worth Tanzanian shillings 150,000 in 2013. After successful repayment of the loan, she qualified for a relatively bigger loan and got Tanzanian shillings 300,000. Before accessing a cheaper loan from her VCONE, she used to get a net profit ranging from Tanzanian shillings 5000 to Tanzanian shillings 11,00O per week. However, after getting a loan from her network, she invested more in the business and as a result, profits raised to Tanzanian shillings 30,00O per week. With this amount, she can be able to support household needs and meet school expenses. More importantly, she is happy that she can support her family and not worry about buying things for herself.

Source: Survey Data.

The success story reflects the findings from FGD and key informant interviews. One explanation for this finding is that VCONEs transform the lives of marginalized women for better. The present study also found that formal rural financial institutions such as SACCOS (Savings and Credit Cooperative Society) are present; however, they are poorly managed and extremely corrupt. Marginalized women can hardly access loans from such 
institutions. FGDs further exposed that women in Mkalama District join VCONEs because the SACCOS existing in the district embrace corruption, exercise nepotism, and oppress disadvantaged women. It also takes a relatively longer to access a loan from a SACCOS than it is the case with VCONEs. That is why VCONEs are seen as saviours of women in the district

Documentary review of some financial institutions -other than SACCOS-, operating in the district, discloses that the institutions also employ group lending scheme. However, the present study found that the institutions, charge relatively higher interest rates than VCONEs. They also employ group lending procedures that are more complicated than those of VCONEs. VCONE member with membership in one of the institutions disclosed that a borrower has to incur around $22 \%$ of the total loan for her application to be considered by one of the mentioned financial institutions. However, a same borrower would incur only $10 \%$ interest to access a similar amount of loan from a VCONE. Subsequently, such financial institutions suffer from low repayment rates and in return seize properties owned by those who fail to repay their loans on time. This makes it extremely difficult for the institutions to meet operating expenses in the district. And as a result, the majority of the institutions have phase out their projects in the district. One explanation for the findings is that difficulties associated with accessing loans from formal financial institutions, pave way for VCONEs to remain the main providers of microfinance services in the District. A second explanation is that a significant number of women find it safer and fairer to join VCONEs, with low interest rates and somewhat relaxed regulations, to access microloans.

An important explanation though is that VCONEs have blocked profit driven neoliberal microfinance institutions from entering the microfinance market in the district. As found in past research on women's collectives (Archambault, 2010; Msonganzila, 1994) VCONEs serve as an important tool to increase women's accessibility to the much needed financial resources through self-help initiatives. VCONEs serve a platform to reinvigorate the selfhelp culture among Mkalama communities.

\subsubsection{Patriarchal Culture}

The prevalence of the patriarchal culture among communities in Mkalama district makes men less reliable and faithful than women (see Table 5). In this regard, the findings highlight that the majority of women prefer to join VCONEs to network with other women. Kuwabara, Zou, Aven, Hildebrand, and Iyengar (2020) highlights the role of beliefs on shaping people's motivation to network. Further, past research highlight that marginalized women are likely to network with other marginalized women (Di Tommaso et al., 2020). The finding supports the present study through showcasing that women believe that men are less reliable. In line with past research conducted elsewhere (see Yunus (2007)) the research shows that women are wary in servicing loans than men. It is almost a rule of the thumb that women in Mkalama District join VCONEs because women in the district are more faithful and reliable than men (see Table 5). An immigrant lady who is also a leader of one of the VCONEs shared the following viewt:

"I am an immigrant from Northern Tanzania. Honestly, men in Mkalama District are unreliable and unfaithful. Men's savings groups often collapse because men do not pay loans. Whenever they face challenges in their household, they oftentimes abandon those families. In so doing, they pass an extra burden to their wives to pay their husband's outstanding loans. Men tend to spend loans lavishly. Nevertheless, women pay their loans because they are faithful and reliable. The main reason being that women's major responsibility is to provide care to the entire household (VCONE secretary, Iguguno village, $17^{\text {th }}$ May, 2015)

The statement is a reflection of the situation in the entire study as revealed by the study findings. The finding highlight that it is risky to grant men membership in VCONEs. The patriarchal culture makes men in Mkalama District less responsible to their households. It is a common practice for men to abandon their households during difficult times as indicated by FGDs held at Iguguno and Kinyangiri (13/05/15) as well as those at Kikhonda and Msingi (14/05/15). The follow up study revealed that some of the men in the study area remain stubborn and 
uncooperative portraying patriarchal domination. In such a situation, some VCONEs have attempted to change the patriarchal culture by allowing a few men into their networks. These men are not allowed to hold any leadership positions. Further, the majority of VCONEs allow husbands of members, especially for those who live far away, to represent their wives in some of the VCONE meetings. Overall, the findings suggest that marginalized women find it more convenient to join "women only" and "women led" VCONEs. This is a diversion away from conversion ROSCA schemes that focus on addressing financial needs of men and women.

\subsubsection{Need for Information}

The findings indicate that marginalized women are always in search of information in an attempt to find better solutions to their challenges. That is, the need for information pushes women to join VCONEs (see Table 5). The finding is consistent with past research highlighting that social networks are an important source of information on which individuals base their opinions and actions (see Vriens and Corten (2018)). VCONEs serve as platforms for exchange of information among members. Findings from FGDs divulged that VCONE members exchange business information. Some of members of VCONEs usually travel to market towns to purchase merchandize for their respective petty businesses. The price for merchandize is cheaper at some of the market. VCONE members share information on wholesale stores whose prices are relatively cheaper. The findings imply that VCONE allows members to spend their funds wisely by purchasing more profitable merchandise. Without such support from fellow VCONE members, it would have been impossible to venture into such risk business

A unique finding of the study is that after observing and talking to a group of 35 members of VCONEs, the findings showed that VCONE and UPATU can be merged. The women entrepreneurs, all of who belonged to the same VCONE, share goods for selling to their customers and information on price for their merchandise. A study by Tripp (1994) done in Dar es Salaam in 1990s divulges that Upatu societies averaged around 12 participants. The participants contributed some money in a kitty each day and then, after 5 days, one of them would claim the entire kitty. Under a similar arrangement but different modalities -three times the number of participants in an ideal traditional Upatu- Mkalama women participate in their Upatu scheme. The women are required to contribute between Tanzanian shillings 2000 and 10,000 to a VCONE every week. They also are required to contribute a total of Tanzanian shillings 10,000 to an UPATU scheme each day. This is an equivalent to Tanzanian shillings 80,000 to be saved each week by every woman for both Upatu and VCONE schemes. Unlike the case with VCONE where women get a loan only when it is available, one of the 35 members receives a lump sum of Tanzanian shillings 350,000 every 35 days. And the cycle goes on.

The saving service is important because it is oftentimes difficult for the women to save money at their household saving. This is elaborated by an experienced member of a VCONE:

"To be honest with you, it is extremely difficult for women to save money by simply keeping it at home. This is because women have many caretaking responsibilities which increase their financial burden. As a result, women, without saving mechanisms, miss the opportunity to save enough money to expand their businesses. Accordingly, we, as women entrepreneurs trading at the market, have established an UPATU scheme so as to serve money without a temptation of spending it on household expenses. The savings enable us to expand our businesses and get more profits" (Mama James', an experienced member of VCONE, Iguguno ward, 23rd May, 2015).

The findings imply that savings mechanisms can equally be helpful to the women in the district and elsewhere. The mentioned UPATU scheme is sustainable in that it has been going on since 2010. Members have become a family in which they share various goods including money and information. The mixing of two different schemes to

${ }^{3}$ Not real name. 
include VCONEs for saving and loaning as well as UPATU scheme for saving is an important innovation that can be replicated elsewhere to empower women.

Consistent with past research on networks (Twigg, 2015) VCONES improves access to, and exchange of, information and expertise. They also allow people to positively engage in dialogues, exchange ideas and experiences, listen to each other and work towards a new way of understanding and solving problem. The findings are also in line with a thesis that networks in countries of the South may engage in microfinance not to make profits but to provide moral and economic support to members (Lo, 2008; Mohanty, 2002). Developmental agencies need to take this view on board whenever they implement similar interventions.

\subsubsection{Lack of Entrepreneurship Skills}

Some of the women are interested in becoming entrepreneurs but they have realised that they lack entrepreneurship skills (see Table 5). The findings of this study unveil that women join VCONEs to access some informal and formal training on entrepreneurship. For instance, $50 \%$ of all female respondents of a semi-structured questionnaire and $37 \%$ of male respondents are of opinion that women join VCONEs because they need to access training on entrepreneurship (see Table 5). The findings support the views of Islam (2012) who argues that one of the major problems facing rural women entrepreneurs in Sub-Saharan Africa is lack of entrepreneurship training. Past research indicates that rural women in Uganda and Kenya fail to create and sustain successful businesses because they lack entrepreneurship training (UNIDO, 2003). In view of that, women need training on business management, marketing and technical skills. Within the neoliberal context, women's capacities are further weakened by weak infrastructure and complicated legal frameworks for operating businesses.

Based on the study findings, nine VCONEs in Iguguno, Kinyangiri, and Khikonda offer informal training to their members. Three networks in Msingi and one in Nduguti make formal arrangements to train members. They either pay for a few members to participate in a formal training or pay a resource person to come to their village to offer them training. To a large degree, VCONEs serve as a platform for accessing entrepreneurship training from experienced local entrepreneurs, local resourceful persons, government experts and other potential development agencies. VCONEs make arrangements for the members to receive training from the members who have received such training already. This is an obligation to those whose training has been paid by VCONEs. VCONEs also have made a special arrangement for the members to take turns in receiving a paid training. In so doing, the majority of members get an opportunity to receive capacity building training in one or two areas of entrepreneurship. These trainings enable the VCONE members to stay up-to-date in their entrepreneurial skills.

The findings also reflect those of the follow up study. That is, training increases the capacity of individual VCONE members to offset exploitative challenges of the market. Key informant interviews highlight that entrepreneurial training has enabled VCONE members to conduct profitable businesses. Those without training operate their businesses with significant losses. VCONE members, among other things, have learnt to avoid being too selective on petty businesses. They select based on needs of the customers at a particular time. Whenever they experience losses, they have learned to switch to other businesses with high demand in the market.

\section{CONCLUSION}

An exploration of "push and pull" factors for establishing or joining VCONEs has provided an understanding of the way marginalized women network to deal with the challenges emanating from neoliberal market and patriarchal culture. VCONEs serve as evidence that marginalized people have the potential to organize and form sustainable community collectives. The study suggests that external driven efforts to network marginalized people ignore context specific needs. As such, such networks fail to sustain themselves. A unique contribution of the study is the application of the push and pulls theory to study social networks. 
Further, the findings of this study support a theory by Verheul et al. (2010). That is, there is an existence of push and pull factors which draw people into social networking and entrepreneurship. An innovative addition to the theory is that VCONE serve as a platform to allow women join small-scale entrepreneurship. Consistent with past research, this research suggest that neoliberal inequalities lead to increased financial needs of the marginalized people including women (Harvey, 2007, 2011; Harvey, 2005; Madaha, 2014; Tripp et al., 2009). In turn, the context creates new survival necessities for individuals in their respect contexts. Further, VCONEs have created a number of pull factors that enable women to address some of the challenges of the neoliberal market.

In line with the social network theory, VCONEs serve as hubs of formal and informal social relationships among members to enable them improve their living standards (see Marineau et al. (2018)). The study further suggests the importance of focusing on the social component of the society by highlighting the shortfalls of exclusive focus on the economy. That is, the finding is consistent with the social economic theory (see (Christoforou, 2018; O'Boyle, 1996)). Finally, the study adds to the Socialist feminism and associated strands synthesize women's oppression by capitalism and patriarchy (see (Kendall, 2007; Madaha, 2014)). The findings highlight the difficulties experienced by women from capitalist neoliberal framework as conjoined by the patriarchal culture.

The study proposes to revisit the National Microfinance policy of 2000 to encourage local community members to join VCONEs. The policy overtly relies on NGOs and financial institutions to provide microfinances services to the poor. The findings of this study have disclosed the failure of such institutions in the provision of the services. The institutions, among other things, have failed to take on board the local contexts. For that reason, the policy needs to be revisited to accommodate VCONEs.

Funding: This study received no specific financial support.

Competing Interests: The author declares that there are no conflicts of interests regarding the publication of this paper.

\section{REFERENCES}

Aina, O. (1998). African women at the grassroots: The silent partners of the women's movement. In Nnaemeka O. (Eds.), Sisterhood, Feminisms and Power: From Africa to the Diaspora (pp. 65-88). Eritrea: Africa World Press Inc.

Archambault, C. S. (2010). Women left behind? Migration, spousal separation, and the autonomy of rural women in Ugweno, Tanzania. Signs: Journal of Women in Culture and Society, 35(4), 919-942. Available at: https://doi.org/10.1086/65 1042.

Biewener, C. (2006). France and Québec, The progressive visions embodied in different social economy traditions. In Clary Betsy Jane, Dolfsma Wilfred, and Figart Deborah M.(Eds.), Ethics and the Market Insights from social economics (pp. 126140). New York: Routledge.

Borgatti, S. P., Mehra, A., Brass, D. J., \& Labianca, G. (2009). Network analysis in the social sciences. Science, 323(5916), 892-895. Brenner, J. (2014). 21 st century socialist feminism. Social Studies, 1O(1), 31-49.

Bujra, J. (1990). Taxing development in Tanzania: Why must women pay? Review of African Political Economy, 17(47), 44-63. Available at: https://doi.org/10.1080/03056249008703847.

Chachage, S. L. C., \& Mbilinyi, M. (2003). Against neo-liberalism: Gender democracy and development. Dar es Salaam: E\&D Limited. Charmaz, K. (2006). Constructing grounded theory. Thousand Oaks, CA: Sage.

Christoforou, A. (2018). Connecting theory with practice: Lessons from Bourdieu. Forum for Social Economics, 47(3-4), 278-287. Available at: https://doi.org/10.1080/07360932.2016.1187190.

Daniel, A. K. (1988). Invisible careers: Women civic leaders from the volunteer world. Chicago: University Chicago Press.

Di Tommaso, G., Gatti, M., Iannotta, M., Mehra, A., Stilo, G., \& Velardi, P. (2020). Gender, rank, and social networks on an enterprise social media platform. Social Networks, 62, 58-67. Available at: https://doi.org/10.1016/j.socnet.2020.02.007. 
Eisenstein, H. (2009). Feminism seduced: How global elites use women's labor and ideas to exploit the world. Boulder, CO: Paradigm Publishers.

Ellwardt, L., Labianca, G. J., \& Wittek, R. (2012). Who are the objects of positive and negative gossip at work?: A social network perspective on workplace gossip. Social Networks, 34(2), 193-205. Available at: https://doi.org/10.1016/j.socnet.2011.11.003.

Enarson, E., \& Morrow, B. H. (1998). The gendered terrain of disaster through women's eyes. USA: Praeger Publishers.

Geiger, S. (1997). TANU women: Gender and culture in the making of Tanganyikan nationalism. Portsmouth: NH: Heinemann.

Harvey, D. (2007). Neoliberalism as creative destruction. Annals of the American Academy of Political and Social Science, 610(1), $21-$ 44.

Harvey, D. (2011). The enigma of capital and the crises of capitalism. New York: Oxford University Press.

Harvey, D. (2014). Seventeen contradictions and the end of capitalism. New York: Oxford University Press.

Harvey, D. (2005). A brief history of neoliberalism. New York: Oxford University Press.

Hyden, G. (1980). Beyond Ujamaa in Tanzania: Underdevelopment and uncaptured peasantry. California: University of California Press

Islam, S. (2012). Pull and push factors towards small entrepreneurship development in Bangladesh. Journal of Research in International Business Management, 2(3), 065-072.

Kabeer, N. (2003). Gender mainstreaming in poverty eradication and the millennium development goals: A handbook for policy-makers and other stakeholders. Ottawa: International Development Research Centre.

Kendall, D. (2007). Sociology in our times: The essentials. USA: Thomson Wadworth.

Kilduff, M., \& Brass, D. J. (2010). Organizational social network research: Core ideas and key debates. Academy of Management Annals, 4(1), 317-357. Available at: https://doi.org/10.1080/19416520.2010.494827.

Koda, B. O., Mbilinyi, M. J., Muro, A., Nkebukwa, A. K., Nkhoma, A. M., Tumbo-Masabo, Z. Z., \& Vuorela, U. (1987). Women Initiatives in the United Republic of Tanzania. A Technical Report, Geneva: ILO.

Kuhn, B. M. (2018). China's commitment to the sustainable development goals: An analysis of push and pull factors and implementation challenges. Chinese Political Science Revierw, 3(4), 359-388. Available at: https://doi.org/10.1007/s41111-018-0108-0.

Kuwabara, K., Zou, X., Aven, B., Hildebrand, C., \& Iyengar, S. (2020). Lay theories of networking ability: Beliefs that inhibit instrumental networking. Social Networks, 62, 1-11. Available at: https://doi.org/10.1016/j.socnet.2020.01.003.

Lo, M. (2008). Public-private partnerships for maternal health in Africa: Challenges and prospects. Marriage $\mathcal{E}^{\circ}$ Family Review, 44(2-3), 214-237. Available at: https://doi.org/10.1080/01494920802 177444.

Madaha, R. (2018). Challenges and opportunities of Village Community Networks within the neoliberal context: A case study of women's networks in Africa. African Identities, 16(1), 50-66. Available at: https://doi.org/10.1080/14725843.2017.1332982.

Madaha, R. M. (2020). Can local African communities be empowered through participatory budgeting? International Journal of Social and Administrative Sciences, 5(2), 74-93. Available at: https://doi.org/10.18488/journal.136.2020.52.74.93.

Madaha, R. (2021). Tanzania. In Stewart, C. (Ed), Gender and identity around the world: Africa, the Americas, Asia, and Oceania (Vol. 1). California: ABC-CLIO.

Madaha, R. (2014). Organized and gendered media advocacy at the centre of the feminist movement in a patriarchal Tanzania. Africa Review, 6(1), 18-29. Available at: https://doi.org/10.1080/09744053.2014.883754.

Mallya, E. (2005). Women NGOs and the policy process in Tanzania: The case of the land act of 1999. African Study Monographs, 26(4), 183-200.

Marineau, J. E., Labianca, G. J., Brass, D. J., Borgatti, S. P., \& Vecchi, P. (2018). Individuals' power and their social network accuracy: A situated cognition perspective. Social Networks, 54, 145-161. Available at: https://doi.org/10.1016/j.socnet.2018.01.006. 
McClean, M. (2000). Alternative approaches to women and development. In Parpart, J. L., Connelly M. P., and Barriteau V. E. (Eds.), Theoretical Perspectives on Gender and Development (pp. 179-190). Ottawa: International Development Research Centre.

Meghji, Z., Meghji, R., \& Kwayu, C. (1985). The women co-operator and development. Experience from Eastern, Central and Southern Africa. Nairobi: Maarifa Publishers Limited.

Mohanty, C. (2002). Women workers and capitalist scripts: Ideologies of domination, common interests and the politics of solidarity. In Holmstrom N. (Ed.), The Socialist Feminist Project: A Contemporary Reader in Theory and Politics (pp. 160-180). New York: Monthly Review Press.

Moser, C. (1993). Gender planning and development: Theory, practice and training. London: Routledge.

Moser, C. O. (1989). Gender planning in the Third World: Meeting practical and strategic gender needs. World Development, 17(11), 1799-1825. Available at: https://doi.org/10.1016/0305-750x(89)90201-5.

Msonganzila, M. R. (1994). Women and cooperatives in Tanzania: Separatism or integration. Economic and Political Weekly, 29(44), 86-96.

Narayan, D. (1999). Bonds and bridges: Social capital and poverty, policy research. Working Paper No. 2167, Poverty Reduction and Economic Management Network, World Bank, Washington, DC.

Nikjoo, A. H., \& Ketabi, M. (2015). The role of push and pull factors in the way tourists choose their destination. Anatolia, 26(4), 588-597. Available at: https://doi.org/10.1080/13032917.2015.1041145.

O’Boyle, E. J. (1996). Social economics: Premises, findings and policies. London: Routledge.

Parpart, J. L., Connelly, M. P., \& Barriteau, V. E. (2000). Theoretical perspectives on gender and development. Otawa: International Development Research Centre.

Putnam, R. (2000). Bowling alone: The collapse and revival of American community. New York: Simon \& Schuster.

Sarker, D. (2006). Development theory and gendered approach to development: A review in the third world perspective. Sociological Bulletin, 55(1), 45-66. Available at: https://doi.org/10.1177/0038022920060103.

Say, J. (1803). Treatise on political economy or simple exposition of the way in which are formed, distributed and consumed ichesses (1st ed.). Paris: Crapelet.

Scott, K., \& Liew, T. (2012). Social networking as a development tool: A critical reflection. Urban Studies, 49(12), $2751-2767$. Available at: https://doi.org/10.1177/0042098011435279.

Solano, G., \& Rooks, G. (2018). Social capital of entrepreneurs in a developing country: The effect of gender on access to and requests for resources. Social Networks, 54, 279-290. Available at: https://doi.org/10.1016/j.socnet.2018.03.003.

Swantz, M., \& Tripp, A. M. (1996). What went right in Tanzania? People's responses to directed development. Dar es Salaam: University of Dar es Salaam Press.

Tenga, N., \& Peter, C. M. (1996). The right to organise as mother of all rights: The experience of women in Tanzania. The Journal of Modern African Studies, 34(1), 143-162. Available at: https://doi.org/10.1017/s0022278x00055245.

Tripp, A. M., Casimiro, I., Kwesiga, J., \& Mungwa, A. (2009). African women's movements: Changing political landscapes. Cambridge: Cambridge University Press.

Tripp, A. M. (1994). Gender, political participation and the transformation of associational life in Uganda and Tanzania. African Studies Review, 37(1), 107-131. Available at: https://doi.org/10.2307/525115.

Tripp, A. M. (1989). Women and the changing urban household economy in Tanzania. The Journal of Modern African Studies, 27(4), 601-623. Available at: https://doi.org/10.1017/s0022278x00020462.

Tulin, M., Mollenhorst, G., \& Volker, B. (2021). Whom do we lose? The case of dissimilarity in personal networks. Social Networks, 65, 51-62. Available at: https://doi.org/10.1016/j.socnet.2020.11.003.

Twigg, J. (2015). Disaster risk reduction. London: ODI.

UNIDO. (2003). Developing rural and women entrepreneurship. Vienna: UNIDO.

URT. (1988). Situation of women in Tanzania. Dar es Salaam: Government Printers and Ministry of Community Development Gender. 
URT. (2000a). Women development and gender policy (2000). Dar es Salaam: Government Printers.

Verheul, I., Thurik, R., Hessels, J., \& Zwan, P. (2010). Factors influencing the entrepreneurial engagement of opportunity and necessity entrepreneurs. Netherlands: SCALE (Scientific Analysis of Entrepreneurship and SMEs).

Vriens, E., \& Corten, R. (2018). Are bridging ties really advantageous? An experimental test of their advantage in a competitive social learning context. Social Networks, 54, 91-100. Available at: https://doi.org/10.1016/j.socnet.2018.01.007.

WinklerPrins, A. M., \& de Souza, P. S. (2005). Surviving the city: urban home gardens and the economy of affection in the Brazilian Amazon. Journal of Latin American Geography, 4(1), 107-127. Available at: https://doi.org/10.1353/lag.2005.0033.

Woolcock, M. (2001). The place of social capital in understanding social and economic outcomes. ISUMA Canadian Journal of Policy Research, 2(1), 11-17.

Woolcock, M., \& Narayan, D. (2000). Social capital: Implications for development theory, research, and policy. The World Bank Research Observer, 15(2), 225-249.

WWF. (2010). VSLA/VICOBAs/COCOBA training manual. Tanzania: WWF.

Yunus, M. (2007). Creating a world without poverty: Social business and the future of capitalism. New York: Public Affairs. 